\title{
Otomatisasi Pintu Air Pada Sistem Pembangkit Listrik Mikrohidro
}

\author{
Evrynda Widyasari Puspa Dewi, Sunardi \\ Program Studi Teknik Elektro, Universitas Ahmad Dahlan \\ Kampus IV, Jalan Ring Road Selatan, Yogyakarta, Indonesia 55166 \\ e-mail: evrynda1400022058@webmail.uad.ac.id, sunardi@mti.uad.ac.id
}

\begin{abstract}
Micro Hydro Power Plant (PLTMH) is one of the alternatives to supply electrical energy, especially for a remote area which cannot be reached by PLN. PLTMH is utilized water flow to produce electrical energy. In PLTMH, there is a sluice located at the front part that is used to flow the water into the turbine. Sluices are usually controlled manually, which had some weaknesses, including poor stability, the constant monitoring of the PLTMH that requires a lot of cost and effort. This research is made a tool that can be working automatically to assist the human role for opening and closing of the sluice using the schedule. The research is used Arduino Uno for input and output processing of the data. The pushbutton has functioned to control the schedule. RTC system block is used as a real-time timer system. $L C D$ block has functioned to access the date and time information. The system setting menu is used for scheduling. Motor DC system is used as driving the motor sluice with the upper and down position. This research showed that the sluice automatization system is capable of assisting the human role caused can be controlled by the monitor centre. This tool has been tested with various conditions: the first experiment in heavy rain conditions then caused high water level, the second experiment when hot wheater then normally water level. In the trial process, this tool is achieved rate of $100 \%$ success..
\end{abstract}

Keywords:PLTMH; Automatic sluice; Arduino Uno; RTC; DC motor

\section{Abstrak}

Pembangkit Listrik Tenaga Mikro Hidro (PLTMH) merupakan salah satu alternatif untuk menyediakan energi listrik terutama untuk daerah terpencil yang jauh dari jaringan PLN. PLTMH memanfaatkan aliran air untuk menghasilkan tenaga listrik. PLTMH memiliki pintu air yang digunakan untuk mengalirkan air menuju turbin. Pintu air umumnya menggunakan pengontrolan secara manual yang memiliki beberapa kelemahan diantaranya kestabilan kurang baik,perlu pemantauan secara langsung dan terus menerus sehingga membutuhkan biaya dan tenaga yang sangat banyak. Penelitian ini membuat alat yang dapat bekerja secara otomatis dalam menggantikan peran manusia untuk secara terjadwal dalam membuka dan menutup pintu air. Penelitian dibangun menggunakan Arduino Uno sebagai blok utama pemroses data input dan output. Input blokpushbutton berfungsi sebagai tombol untuk mengatur penjadwalan. Input blok sistem RTCberfungsi sebagai sistem pewaktu secara real time. Blok keluaran LCD digunakan sebagai informasi jam,tanggal dan menu setting untuk mengatur penjadwalan. Blok sistem motor DC sebagai penggerak pintu air supaya bergerak naik turun. Penelitian sistem otomatisasi pintu air ini telah mampu menggantikan peran manusia sehingga tidak perlu ada petugas yang menjaga. Alat ini telah diuji coba dengan berbagai kondisi yaitu pada percobaan pertama pada kondisi hujan deras sehingga debit air tinggi, percobaan kedua pada saat panas tetapi debit air sedikit tinggi dan percobaan ketiga saat cuaca panas dan debit air normal. Pada proses percobaan tersebut alat ini mampu bekerja sesuai jadwal yang telah ditentukan dengan tingkat keberhasilan $100 \%$.

Kata Kunci:PLTMH; Pintu air otomatis; Arduino Uno; RTC; Motor DC

\section{Pendahuluan}

Listrik merupakan salah satu kebutuhan pokok bagi masyarakat. Berdasarkan data Direktorat Jenderal Ketenagalistrikan pada awal tahun 2011 angka rasio elektrifikasi nasional baru berada di angka 67,15\%, sedangkan pada akhir tahun 2016 angka ini telah mencapai 
$91,15 \%$. Rata-rata kenaikan $4,75 \%$ per tahun ini merupakan rata-rata kenaikan tertinggi selama ini. Sebelum tahun 2010 rata-rata kenaikan rasio elektrifikasi hanya sekitar 0,7-0,8\% per tahun [1].

Di sisi lain Indonesia memiliki begitu banyak potensi air yang belum dimanfaatkan secara optimal, yaitu sekitar $75.000 \mathrm{MW}$ dan yang termanfaatkan saat ini hanya $10,1 \%$ atau sebesar 7,572 MW. Potensi untuk mini/mikrohidro sebesar 1,2 GW untuk 240 unit PLTMH dengan masing-masing PLTMH 5 MW pada tahun 2014 [2]. Mikrohidro dikenal sebagai white resources dengan terjemahan bebas bisa dikatakan "energi putih". Dikatakan demikian karena instalasi pembangkit listrik seperti ini menggunakan sumber daya yang telah disediakan oleh alam dan ramah lingkungan. Mikro artinya kecil sedangkan hidro artinya air. Istilah mikrohidro bukan sesuatu yang baku namun bisa dipastikan bahwa Mikrohidro pasti mengunakan air sebagai sumber energinya [3].

Pembangkit Listrik Tenaga Mikrohidro (PLTMH) adalah suatu sistem pembangkit listrik yang dapat mengubah potensi air dengan ketinggian dan debit tertentu menjadi tenaga listrik dengan menggunakan turbin air dan generator [4]. Energi alternatif terbagi menjadi dua bagian, yakni energi terbarukan dan tidak terbarukan. PLTMH merupakan salah satu energi yang dapat diperbaharui dan satu energi yang semakin dikembangkan[5]. Pengaruh kapasitor terhadap tegangan keluaran generator induksi pada kondisi terhubung beban yaitu semakin besar beban nilai tegangan keluaran generator induksi semakin turun, nilai tegangan keluaran sangat berpengaruh pada beban. Semakin besar suatu nilai beban yang terhubung pada generator induksi mengakibatkan nilai susut tegangan yang besar juga. Regulasi tegangan yang buruk merupakan salah satu kelemahan generator induksi [6].

PLTMH memiliki pintu air di bagian bak penampung yang digunakan untuk mengalirkan air menuju turbin. Pintu air yang ada saat ini umumnya menggunakan pengontrolan secara manual yang memiliki beberapa kelemahan diantaranya kestabilan yang masih kurang baik dan dilakukannya pemantauan pada PLTMH secara langsung dan terus menerus sehingga membutuhkan biaya dan tenaga yang banyak [7].

Perangkat otomatis sebuah sistem kontrol berfungsi meminimalisir human error atau kesalahan manusia yang bisa berakibat fatal, secara air adalah sumber daya paling dibutuhkan dalam kehidupan sehari-hari [8]. Hampir semua aspek manusia telah mengalami perkembangan pesat [9]. Perkembangan ini didukung oleh kemajuan elektronik dan teknologi informasi. Sudah banyak alat yang tercipta secara otomatis untuk membantu pekerjaan manusia. Penggunaan alat secara manual kini telah banyak digantikan dengan sistem otomatis dan membantu manusia dalam mengerjakan sesuatu berbagai hal.

Penelitian ini dilakukan untuk membantu memecahkan masalah kebutuhan energi listrik di Kalilajar Kretek Kabupaten Wonosobo Jawa Tengah, sehingga perancangan yang dilakukan disesuaikan dengan kondisi lokasi tempat PLTMH dibangun. Pengontrolan otomatis dalam penelitian ini digunakan untuk mengatur buka/tutup pintu air otomatis sesuai jadwal yang ditetapkan. Pengendali menggunakan Arduino Uno sebagai salah satu cara untuk membuat sistem otomatisasi yang memiliki komponen berbasis mikrokontroler pada ATmega328 digunakan untuk mengontrol, menyimpan dan mengolah data [10].

\section{Metode Penelitian}

\subsection{Perancangan Blok Diagram}

Blok digram terdiri dari sistem kontrol arduinoyang bertugas sebagai pengendali waktu serta melakukan pengolahan data.Cara kerja blok diagram berdasarkan Gambar 1. Arduino Uno $\mathrm{R} 3$ sebagai pengolah data dengan inputan $5 \mathrm{~V}$ mendapat masukkan dari tombol back, setting dan next untuk mengatur penjadwalan buka/tutup pintu air dengan RTC sebagai inputan untuk penyimpanan waktu yang telah diatur.

Selanjutnya LCD sebagai output keluaran penjadwalan dari waktu yang telah ditentukan, motor driver mendapat keluaran dari arduino untuk menggerakkan motor DC agar bergerak naik (forward) dan turun (reverse) dengan mendapat catu daya sebesar $24 \mathrm{~V}$. 


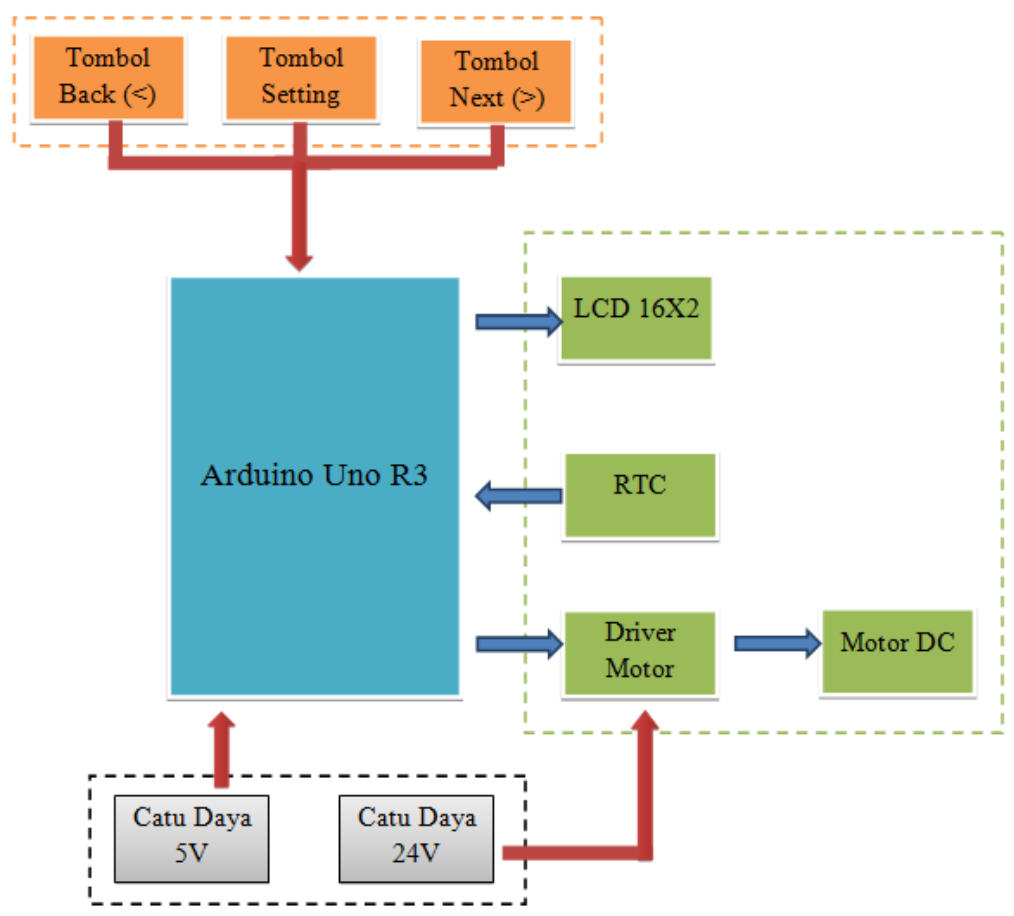

Gambar 1. Blok diagram otomatisasi pintu air pada sistem pembangkit listrik mikrohidro

\subsection{Rangkaian Skematik}

Rangkaian skematik sistem otomatisasi pintu air pada sistem pembangkit listrik mikrohidro dapat dilihat pada Gambar 2.

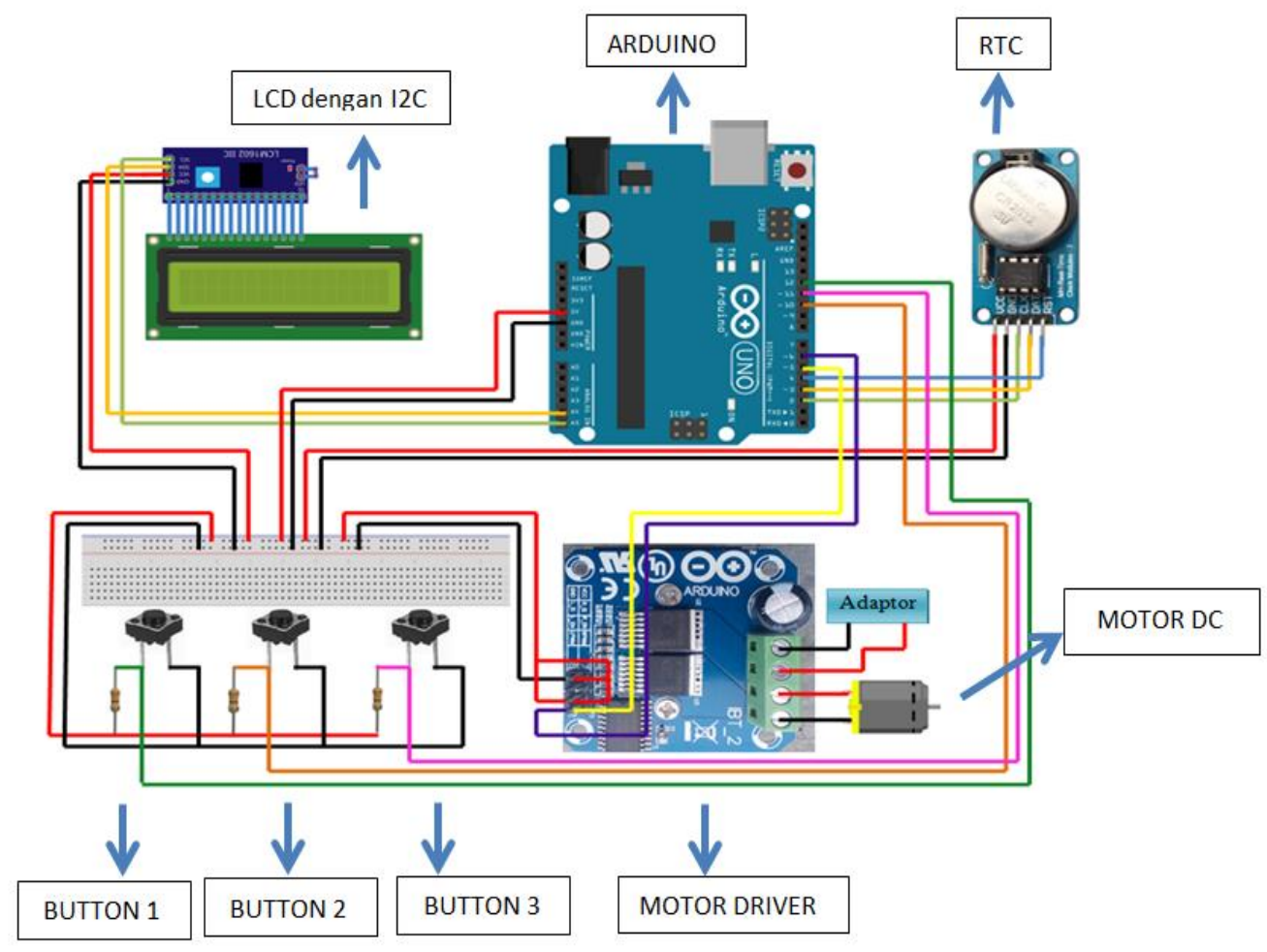

Gambar 2. Rangkaian skematik 
Pin yang digunakan pada arduino dengan komponen lainnya terdapat pada Tabel 1 , Tabel 2, Tabel 3 dan Tabel 4 berikut:

Tabel 1. Pin yang digunakan pada arduino dengan motor driver

\begin{tabular}{cc}
\hline Keterangan & Pin \\
\hline RPWM & $\sim 5$ \\
\hline R_EN & Vcc 5V \\
\hline Vcc & Vcc 5V \\
\hline LPWM & $\sim 6$ \\
\hline L_EN & Vcc 5V \\
\hline
\end{tabular}

Tabel 2. Pin yang digunakan pada arduino dengan RTC

\begin{tabular}{cc}
\hline Keterangan & Pin \\
\hline CLK & 2 \\
\hline DAT & $\sim 3$ \\
\hline RST & 4 \\
\hline VCC & $5 \mathrm{~V}$ \\
\hline GND & GND \\
\hline
\end{tabular}

Tabel 3. Pin yang digunakan pada arduino dengan LCD menggunakan i2c

\begin{tabular}{cc}
\hline Keterangan & Pin \\
\hline SCL & A5 \\
\hline SDA & A4 \\
\hline VCC & $5 V$ \\
\hline GND & GND \\
\hline
\end{tabular}

Tabel 4. Pin yang digunakan pada arduino dengan tombol button

\begin{tabular}{cc}
\hline Keterangan & Pin \\
\hline Button1 & $\sim 10$ \\
\hline Button2 & $\sim 11$ \\
\hline Button3 & $\sim 12$ \\
\hline
\end{tabular}

Cara kerja pada rangkaian skematik pada Gambar 2 adalah Arduino Uno R3 digunakan sebagai pengolah data dari bahasa $\mathrm{C}_{++}$berupa perintah untuk mengoperasikan suatu sistem, sehingga output dari hasil pengolahan tersebut dapat sesuai dengan yang diinginkan. Catu daya $24 \mathrm{~V}$ dari adaptor digunakan sebagai input tegangan modul driver kemudian mensuplai ke motor DC sebagai switching agar motor DC dapat bekerja secara forward-reverse (naik-turun). Catu daya 5V sebagai input Arduino Uno digunakan untuk mengoprasikan suatu sistem. Modul driver digunakan sebagai alat untuk menggerakan motor DC agar dapat disuplai dengan tegangan $24 \mathrm{~V}$ dan dapat bekerja secara forward-reverse (naik-turun). LCD 16x2 digunakan sebagai alat utuk menampilkan waktu secara aktual dan waktu penjadwalan. Real Time Clock (RTC) digunakan sebagai sumber data waktu baik berupa data jam, hari, bulan maupun tahun. Motor DC digunakan sebagai aktuator untuk membuka dan menutup pintu air. Tombol Setting, tombol next (>) dan tombol back (<) digunakan untuk mengatur penjadwalan waktu.

\subsection{Desain Pintu Air}

Desain otomatisasi pintu air pada sistem pembangkit listrik mikrohidro dapat dilihat pada Gambar 3. Gambar 3, merupakan desain pintu air yang digunakan pada penelitian. Nomor 1 adalah Motor DC yang berfungsi untuk menggerakkan drat agar bergerak naik turun, nomor 2 adalah drat untuk menggerakkan pintu air, nomor 3 sebagai pintu air untuk buka tutup pintu air dan nomor 4 yaitu pipa untuk aliran air sebelum masuk ke turbin. 


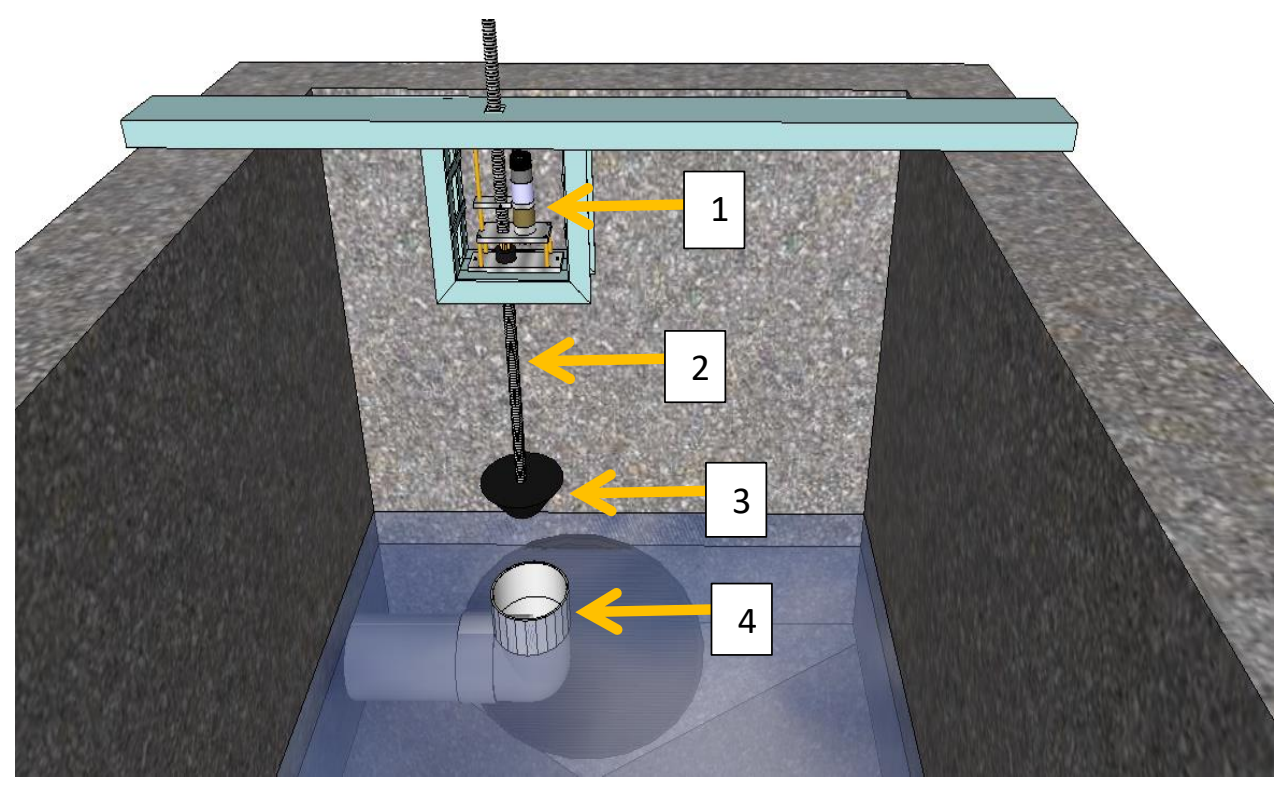

Gambar 3. Desain pintu air

\subsection{Perancangan Flowchart Otomatisasi Pintu Air}

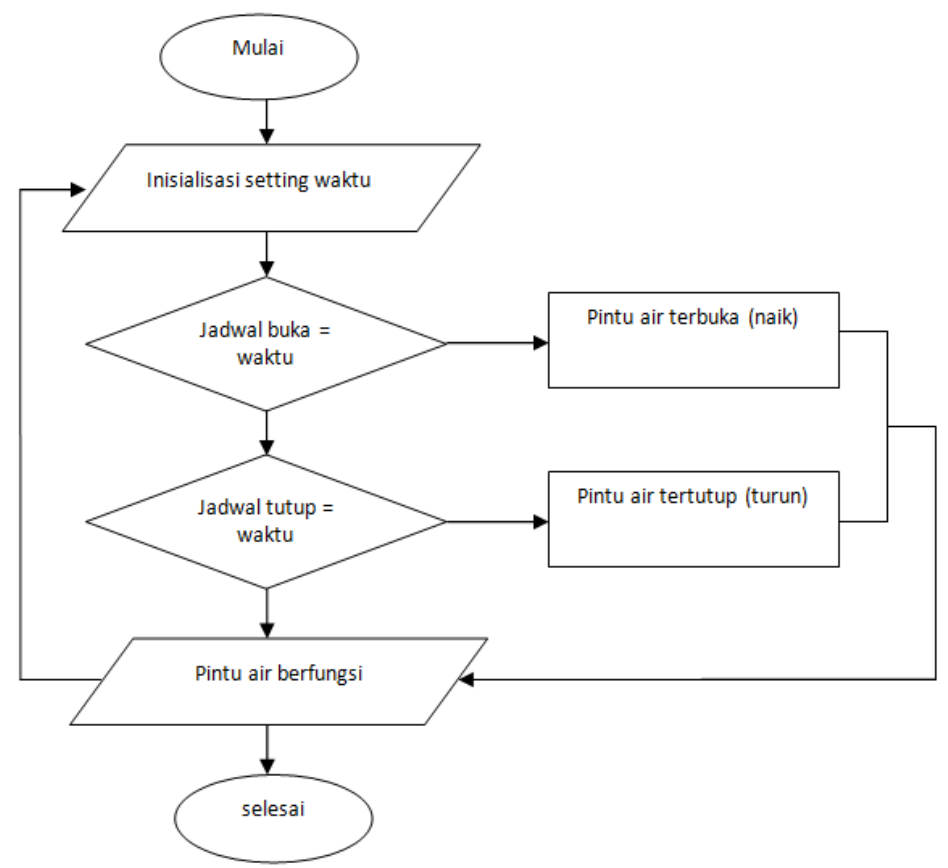

Gambar 4. Diagram alir otomatisasi pintu air

Pada diagram alir (flowchart) seperti Gambar 4, proses yang dilakukan bermula dari awal inisialisasi setting waktu hingga proses eksekusi menggunakan motor DC. Alat ini bekerja menggunakan sistem penjadwalan, waktu buka-tutup dapat diatur sesuai kebutuhan pengguna. Jika jadwal buka maka motor DC akan bekerja secara forward untuk membuka pintu air dan jika jadwal tutup maka motor DC akan bekerja menutup (reverse) untuk menutup pintu air.

Pengujian sistem dilakukan dengan penjadwalan berdasarkan kondisi yang ada untuk mendapatkan jadwal bukaan pintu air dengan waktu yang tepat. Pada pengujian terhadap keseluruhan sistem ini berguna untuk mengetahui kinerja dan tingkat keberhasilan dari sistem tersebut. 


\section{Hasil dan Pembahasan}

Pada tahap pengujian alat, yang dilakukan adalah dengan menguji semua perangkat yang dibuat seperti pada Gambar 5. Dalam pengujian kita harus dapat memastikan perangkat yang kita buat sudah bisa berfungsi sebagaimana fungsi dari masing-masing perangkat.

\subsection{Pengujian Sistem}

Pengujian sistem secara keseluruhan, dibuat melalui penjadwalan berdasarkan kondisi yang ada untuk mendapatkan jadwal bukaan pintu air dengan waktu yang tepat. Setiap kondisi memiliki simbol "1" untuk pintu air terbuka dan "0" untuk pintu air tertutup. Percobaan ini dilakukan sebanyak 3 kali dalam waktu (hari) dan kondisi yang berbeda dengan menggunakan alat seperti Gambar 5.

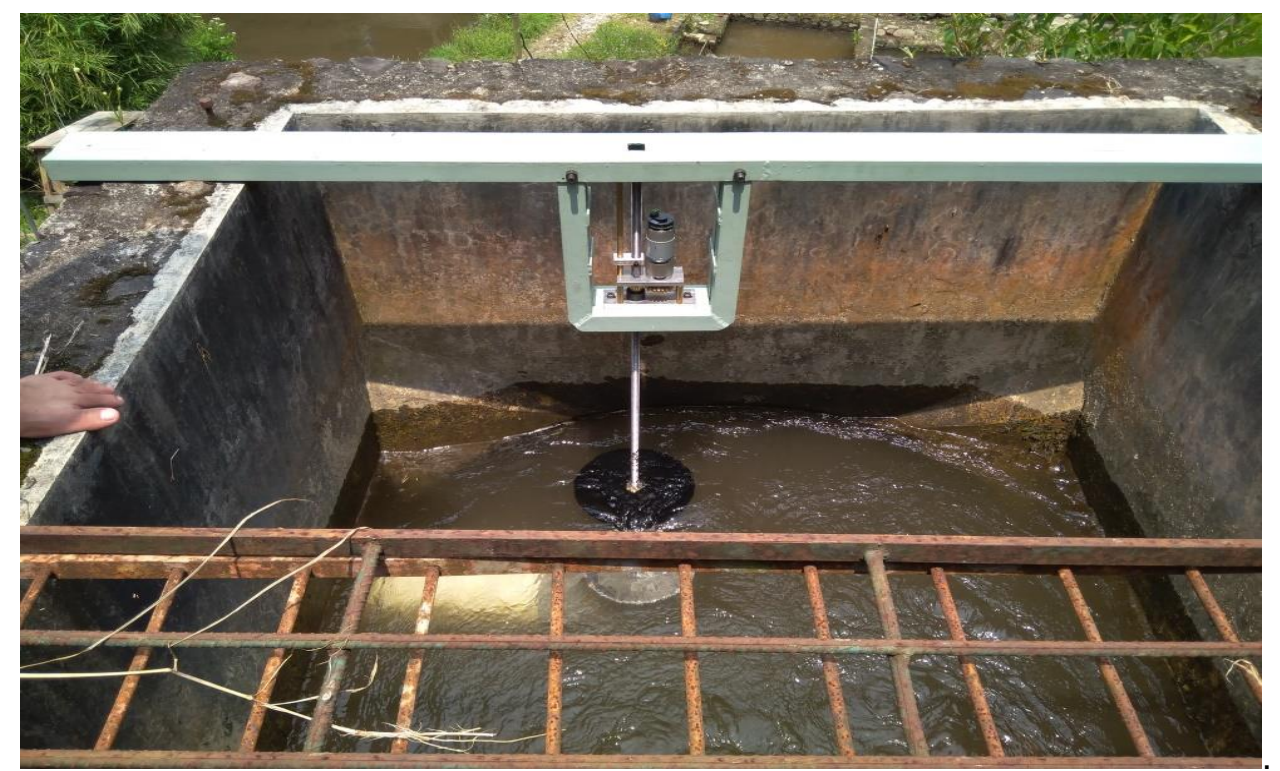

Gambar 5. Alat buka tutup pintu air

Tabel 5. Percobaan pertama

\begin{tabular}{ccccc}
\hline $\begin{array}{c}\text { Kondisi } \\
\text { awal }\end{array}$ & $\begin{array}{c}\text { Mulai } \\
\text { buka/tutup }\end{array}$ & $\begin{array}{c}\text { Durasi } \\
\text { proses } \\
\text { buka/tutup } \\
\text { (detik) }\end{array}$ & $\begin{array}{c}\text { selesai } \\
\text { buka/tutup }\end{array}$ & Kondisi akhir \\
\hline 0 & $15: 25: 00$ & 12 & $15: 25: 12$ & 1 \\
\hline 1 & $15: 30: 00$ & 12 & $15: 25: 12$ & 0 \\
\hline
\end{tabular}

Tabel 6. Percobaan kedua

\begin{tabular}{|c|c|c|c|c|}
\hline kondisi awal & $\begin{array}{c}\text { Mulai } \\
\text { buka/tutup }\end{array}$ & $\begin{array}{c}\text { Durasi } \\
\text { proses } \\
\text { buka/tutup } \\
\text { (detik) }\end{array}$ & $\begin{array}{c}\text { selesai } \\
\text { buka/tutup }\end{array}$ & Kondisi akhir \\
\hline 0 & 09:10:00 & 12 & 09:10:12 & 1 \\
\hline 1 & 09:15:00 & 12 & $09: 16: 12$ & 0 \\
\hline 0 & 09:34:00 & 12 & $09: 34: 12$ & 1 \\
\hline 1 & 09:42:00 & 12 & $09: 42: 12$ & 0 \\
\hline 0 & 10:02:00 & 12 & 10:02:12 & 1 \\
\hline
\end{tabular}

Pada Tabel 5 percobaan pertama dengan kondisi awal pintu air tertutup " 0 ", berdasarkan penjadwalan waktu buka yaitu 15:25:00 dan waktu tutup 15:30:00 dengan jeda waktu 5 menit dan durasi proses hingga pintu buka/tutup 12 detik. Saat kondisi "1" pintu air terbuka dan kondisi 
"0" pintu air tertutup perlu waktu 12 detik. Pada percobaan pertama ini dilakukan untuk memastikan bahwa alat sudah bekerja dengan baik. Hal ini ditandai dengan buka/tutup sesuai dengan jadwal yang ditetapkan dan durasi proses buka/tutup sesuai dengan pengaturan yang diberikan. Selanjutnya dilakukan percobaan kedua dan ketiga dengan durasi proses buka/tutup 10 detik jeda kondisi buka tutup selama 1 menit.

Berdasarkan Tabel 6 percobaan kedua dilakukan tiga kali pengujian dengan alat berhasil melakukan kondisi awal/akhirsesuai dengan jadwal yang ditetapkan.

Tabel 7. Percobaan ketiga

\begin{tabular}{|c|c|c|c|c|}
\hline $\begin{array}{l}\text { Kondisi } \\
\text { awal }\end{array}$ & $\begin{array}{c}\text { Mulai } \\
\text { buka/tutup }\end{array}$ & $\begin{array}{c}\text { Durasi } \\
\text { proses } \\
\text { buka/tutup } \\
\text { (detik) }\end{array}$ & $\begin{array}{c}\text { selesai } \\
\text { buka/tutup }\end{array}$ & $\begin{array}{l}\text { Kondisi } \\
\text { akhir }\end{array}$ \\
\hline 0 & 13:05:00 & 10 & $13: 05: 10$ & 1 \\
\hline 1 & 13:06:00 & 10 & $13: 06: 10$ & 0 \\
\hline 0 & 13:07:00 & 10 & 13:07:10 & 1 \\
\hline 1 & 13:08:00 & 10 & 13:08:10 & 0 \\
\hline 0 & 13:09:00 & 10 & 13:09:10 & 1 \\
\hline 1 & 13:10:00 & 10 & 13:10:10 & 0 \\
\hline 0 & 13:11:00 & 10 & $13: 11: 10$ & 1 \\
\hline 1 & 13:12:00 & 10 & 13:12:10 & 0 \\
\hline 0 & 13:13:00 & 10 & 13:13:10 & 1 \\
\hline 1 & 13:14:00 & 10 & $13: 14: 10$ & 0 \\
\hline 0 & 13:15:00 & 10 & $13: 15: 10$ & 1 \\
\hline 1 & 13:16:00 & 10 & $13: 16: 10$ & 0 \\
\hline 0 & 13:17:00 & 10 & 13:17:10 & 1 \\
\hline 1 & 13:18:00 & 10 & 13:18:10 & 0 \\
\hline 0 & 13:19:00 & 10 & 13:19:10 & 1 \\
\hline 1 & $13: 20: 00$ & 10 & $13: 20: 10$ & 0 \\
\hline 0 & $13: 21: 00$ & 10 & $13: 21: 10$ & 1 \\
\hline 1 & 13:22:00 & 10 & $13: 22: 10$ & 0 \\
\hline 0 & 13:23:00 & 10 & 13:23:10 & 0 \\
\hline 1 & $13: 24: 00$ & 10 & $13: 24: 10$ & 1 \\
\hline 0 & $13: 25: 00$ & 10 & $13: 25: 10$ & 0 \\
\hline 1 & $13: 26: 00$ & 10 & $13: 26: 10$ & 1 \\
\hline
\end{tabular}

Berdasarkan hasil pengamatan Tabel 7 didapatkan nilai persentase keberhasilan 100\%, artinya alat ini bekerja dengan baik dikarenakan jadwal bukaan dan tutup pintu air bekerja sesuai dengan jadwal yang telah ditentukan.

\subsection{Pengujian Tingkat Kebocoran}

Pada tabel 8 merupakan tingkat kebocoran pada saat kondisi pintu air telah tertutup. Pengambilan sampel kebocoran pada percobaan ke-1 sampai ke-5 dilakukan saat cuaca cerahdidapatkan rata-rata 4,8 liter per 5 detik, sedangkan Tabel 9, percobaan ke-1 sampai ke- 5 dilakukan saat kondisi hujan dan air disungai banjir didapatkan rata-rata 7,6 liter per 5 detik.

Tabel 8. Tingkat kebocoran

\begin{tabular}{ccc}
\hline Percobaan ke- & $\begin{array}{c}\text { Waktu } \\
\text { (detik) }\end{array}$ & $\begin{array}{c}\text { Tingkat kebocoran } \\
\text { (Liter) }\end{array}$ \\
\hline 1. & 5 & 4,5 \\
\hline 2. & 5 & 5,5 \\
\hline 3. & 5 & 5,0 \\
\hline 4. & 5 & 4,5 \\
\hline 5. & 5 & 4,5 \\
\hline Rata-rata & 5 & 4,8 \\
\hline
\end{tabular}


Tabel 9. Tingkat kebocoran

\begin{tabular}{ccc}
\hline Percobaan ke- & $\begin{array}{c}\text { Waktu } \\
\text { (detik) }\end{array}$ & $\begin{array}{c}\text { Tingkat kebocoran } \\
\text { (Liter) }\end{array}$ \\
\hline 1. & 5 & 7,5 \\
\hline 2. & 5 & 8,0 \\
\hline 3. & 5 & 7,5 \\
\hline 4. & 5 & 7,5 \\
\hline 5. & 5 & 7,5 \\
\hline Rata-rata & 5 & 7,6 \\
\hline
\end{tabular}

\section{Kesimpulan}

Berdasarkan hasil pengamatan penjadwalan buka tutup pintu air didapatkan rata-rata tingkat keakurasian pada alat ini yaitu $100 \%$ sehingga dapat disimpulkan bahwa alat bekerja dengan baik dan optimal. Pada tingkat kebocoran pipa diperoleh rata-rata 6,2 liter per 5 detik dalam jeda waktu beberapa detik saat pintu air telah tertutup dengan dilakukan pengamatan dua kali dalam cuaca yang berbeda. Dalam pembuatan alat ini harus dibuat sedemikian rupa agar dalam pelaksanaan tidak terjadi kerusakan. Diharapkan alat otomatisasi buka tutup pada pintu air ini dapat membantu petugas dalam pengontrolan PLTMH.

\section{Referensi}

[1] Kementrian Energi dan Sumber Daya Energi. (2017). Rasio Elektrifikasi Lima Tahun Terakhir. 28 April 2018.

[2] Puskom KESDM. "Kebijakkan Pengembangan Air". 28 April 2018.

[3] Dream Indonesia. "Panduan Sederhana Pembangunan Pembangkit Listrik Tenaga Mikrohidro". 09 Juli 2017.

[4] Arismunandar, Susumumu Kuwahara. "Pembangkitan Dengan Tenaga Air". Buku Pegangan Teknik Tenaga Listrik. Jilid I. Jakarta . Pradnya Paramita, 1974.

[5] Abdulkadir, E. "Energi". Universitas Indonesia Press. Jakart, 1995.

[6] Bhaduria, P., and llyas, M. (2013). Voltage and Frequency Control Asynchronous Generator for an Isolated Wind Energy Conversion System. International Journal of Science and Research (IJSR).

[7] Hardiansyah, E. Firmansyah., dan M. Isnaeni,B.S. "Pengendalian Beban Generator Secara Otomatis dengan Algoritma PID pada PLTMH Berbasis PLC". Jurnal Teknologi, vol.5, no. 2, hal. 114-121, 2012.

[8] Peter Jeranyama. "Irrigation Water Management". Canberry Chart Book University of Massachusetts Amherst, hal. 56-58, 2013.

[9] Clary, M. "Interfacing to an LCD Screen Using an Arduino", hal. 1-9, 2015.

[10] Arif G., A. Oktafeni dan W. Khabzli. "Pemantauan Pembangkit Listrik Tenaga Mikrohidro (PLTMH). Jurnal Rekayasa Elektrika .vol. 10, no. 4, 2013. 